Check for updates

Cite this: RSC Adv., 2018, 8, 35170

\title{
Epoxy composites with functionalized molybdenum disulfide nanoplatelet additives
}

\author{
Ming Zhao, ${ }^{\text {ab }}$ Lizhu Liu, (D) *ac Bin Zhang, ${ }^{\text {b }}$ Mingming Sun, ${ }^{\mathrm{b}}$ Xugang Zhang, ${ }^{\mathrm{b}}$ \\ Xue Zhang, ${ }^{\mathrm{b}}$ Jianhui Li ${ }^{\mathrm{b}}$ and Lei Wang ${ }^{\mathrm{b}}$
}

As a typical layered inorganic analogue of graphene, molybdenum disulfide $\left(\mathrm{MoS}_{2}\right)$ has gained intensive attention and become a research hotspot due to its unique two dimensional nanostructure and excellent properties. The enhancement in the thermal and mechanical properties of polymer/inorganic nanosheet composites depends strongly on their interfacial interaction. In this study, we exfoliated bulk $\mathrm{MoS}_{2}$ into nanosheets which were subsequently functionalized using 3-mercaptopropyltriethoxysilane. The functionalized $\mathrm{MoS}_{2}$ ( $\mathrm{f}-\mathrm{MoS}_{2}$ ) were dispersed in epoxy polymers at loading fractions of up to $1 \%$ by weight via ultrasonication and three roll mills. We characterized the tensile, fracture and adhesive properties of the composite and show that $\mathrm{f}-\mathrm{MoS}_{2}$ nanoplatelets are highly effective at enhancing the mechanical properties of the epoxy at very low nanofiller loading fractions $(0.1-0.7 \%$ by weight). Our results show the potential of functionalized $2 \mathrm{D}$ sheets of transition metal dichalcogenides as reinforcing additives in polymeric composites. The results indicate that the glass transition temperature increases significantly for the lower weight fraction composites, from $135{ }^{\circ} \mathrm{C}$ for the baseline (unfilled) epoxy to $146{ }^{\circ} \mathrm{C}$ at $0.7 \% \mathrm{f}-\mathrm{MoS}_{2}$ loading. The apparent shear strength at $120{ }^{\circ} \mathrm{C}$ increases significantly for the lower weight fraction composites, from 13.8 MPa for the baseline (unfilled) epoxy to $24.9 \mathrm{MPa}$ at $0.7 \% \mathrm{f}$ $\mathrm{MoS}_{2}$ loading.

Received 6th September 2018 Accepted 8th October 2018

DOI: $10.1039 / \mathrm{c} 8 \mathrm{ra07448h}$

rsc.li/rsc-advances inorganic nano-fillers/polymer composites depend strongly on two factors: one is the interaction between the nano-fillers and the polymer matrix; the other is the dispersion state of nanofillers in the polymer matrix...$^{22,23}$ The exfoliation degree of bulk $\mathrm{MoS}_{2}$ is very important to fabricate its polymer nanocomposites with effective reinforcement. The layered structure of $\mathrm{MoS}_{2}$ enables easy intercalation of lithium ions $\left(\mathrm{Li}^{+}\right)$. It is convenient to prepare the polymer nanocomposites by the intercalation of $\mathrm{Li}^{+}$and then exfoliation to a single or few layers through the hydrolysis of the $\mathrm{Li}^{+}{ }^{+24,25}$ Therefore, most of the $\mathrm{MoS}_{2}$ /polymer composites are focused on water-soluble polymers such as poly(vinyl alcohol), ${ }^{26}$ poly(ethylene oxide), ${ }^{27}$ and chitosan, ${ }^{28}$ prepared through a solution blending method.

In this study, we exfoliated bulk $\mathrm{MoS}_{2}$ into nanosheets which was subsequently functionalized using 3-mercaptopropyltriethoxysilane. We characterized the tensile and fracture and adhesive properties of the composite and show that $\mathrm{f}$ $\mathrm{MoS}_{2}$ nanoplatelets are highly effective at enhancing the mechanical properties of the epoxy at very low nanofiller loading fractions.

\section{Experimental}

\subsection{Materials}

Molybdenum disulfide, $n$-hexane and tetrahydrofuran were purchased from Sinopharm Chemical Reagent Co., Ltd. 


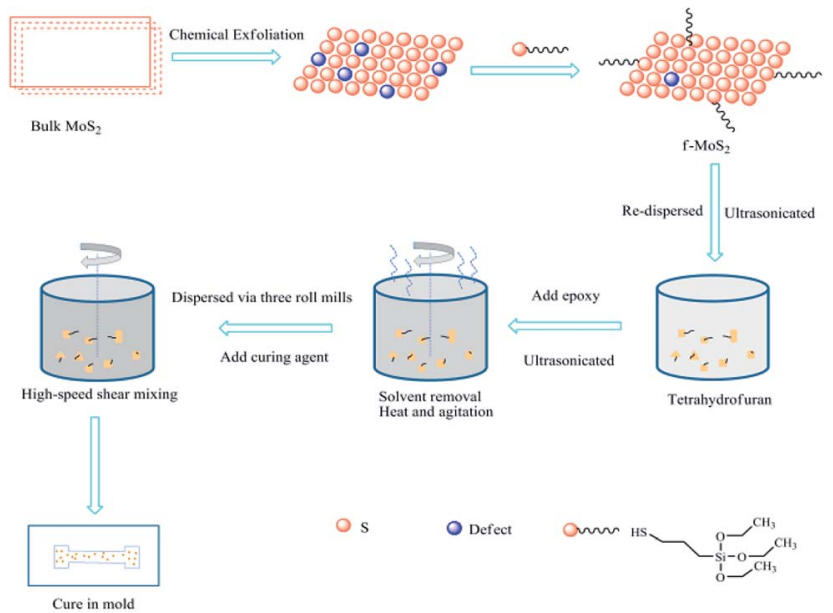

Scheme 1 Schematic illustration of $\mathrm{f}-\mathrm{MoS}_{2}$ /epoxy composite preparation route.

(China). The $n$-butyl lithium (2.2 $\mathrm{M}$ in hexane) was purchased from Alfa Aesar without further purification. Diglycidyl ether of Bisphenol-F type epoxy resin (NPEF-170) were purchased from Nan Ya Plastics Corporation. 3,3'-Dimethyl-4,4'-diaminodicyclohexylmethane (DMDC) were purchased from BASF. 3Mercaptopropyltriethoxysilane (KH580) were purchased from Nanjing Shuguang Chemical Group Co., Ltd. Deionized water is used for all experiments unless otherwise stated.

\subsection{Synthesis of functionalized $\mathrm{MoS}_{2}$ nanosheets}

$\mathrm{Li}_{x} \mathrm{MoS}_{2}$ was prepared by the solvothermal methodology, similar to the preparation procedure of $\mathrm{Li}_{x} \mathrm{WS}_{2}$. In a typical experiment, $1.0 \mathrm{~g}$ bulk $\mathrm{MoS}_{2}$ powder was soaked in the autoclave and $36 \mathrm{~mL} 0.5 \mathrm{M}$ solution of $n$-butyl lithium in hexane was then added. The autoclave was tightly sealed and heated at $90{ }^{\circ} \mathrm{C}$ for $4 \mathrm{~h}$. Following the intercalation by lithium, the $\mathrm{MoS}_{2}$ sample was filtered and washed with anhydrous hexane, and then dried at $50{ }^{\circ} \mathrm{C}$ in vacuum oven. Exfoliation of $\mathrm{MoS}_{2}$ into nanosheets was achieved via the rapid hydrolysis and ultrasonication of $\mathrm{Li}_{x} \mathrm{MoS}_{2}$. In a typical reaction, $0.5 \mathrm{~g} \mathrm{Li} \mathrm{LMOS}_{2}$ was hydrolysed in $1 \mathrm{~L}$ water, and ultrasonicated at ambient temperature for $4 \mathrm{~h}$ to produce a colloidal suspension of $\mathrm{MoS}_{2}$ nanosheets. For the functionalization of $\mathrm{MoS}_{2}$ nanosheets, $1.0 \mathrm{~g}$ of $\mathrm{KH} 580$ was added into $0.25 \mathrm{~g}$ of $\mathrm{MoS}_{2}$ nanosheets dispersed in $500 \mathrm{~mL}$ of water. After sonication for $20 \mathrm{~min}$ and stirring overnight, excess KH580 was removed by filtration followed by several times of water washing. The obtained $\mathrm{f}-\mathrm{MoS}_{2}$ was dried in a vacuum oven at $50{ }^{\circ} \mathrm{C}$ for 12 hours.

\subsection{Preparation of $\mathbf{f}-\mathrm{MoS}_{2} /$ epoxy nanocomposites}

Scheme 1 illustrates the procedure for preparing f-MoS $\mathrm{M}_{2} / \mathrm{epoxy}$ nanocomposites. The f-MoS $/$ /epoxy nanocomposites were prepared by the solvent blending method and grinding method, maintaining the nanofiller loading at $0.1 \mathrm{wt} \%, 0.3 \mathrm{wt} \%$, $0.5 \mathrm{wt} \%, 0.7 \mathrm{wt} \%$ and $1 \mathrm{wt} \%$, respectively. First, the calculated $\mathrm{f}-$ $\mathrm{MoS}_{2}$ nanosheets were re-dispersed in tetrahydrofuran and

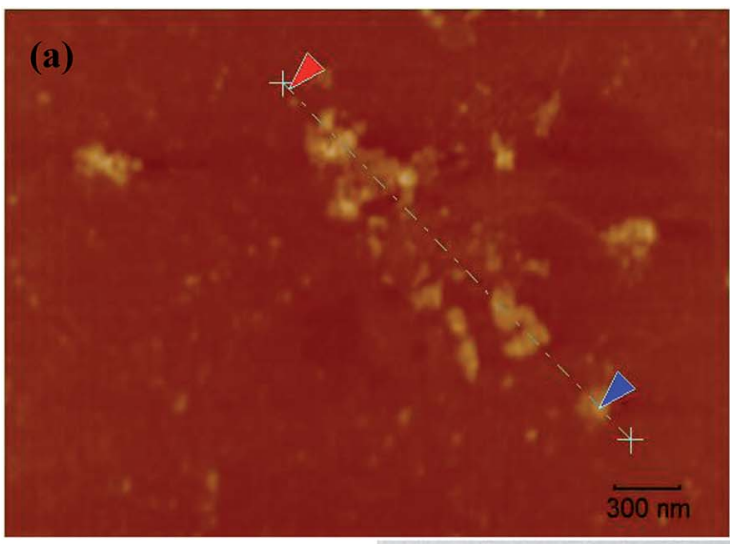

(b)

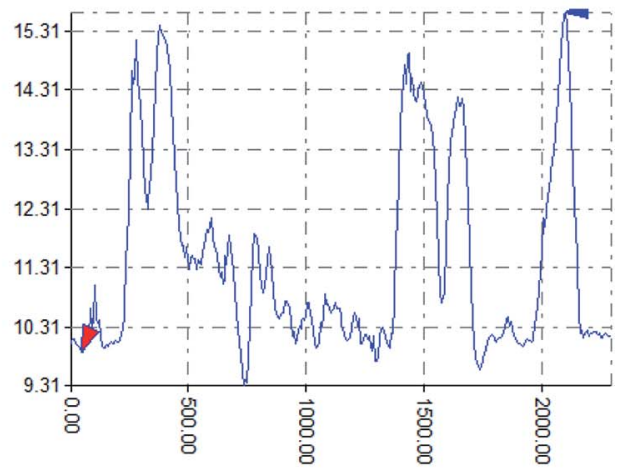

$\mathrm{nm}$

(c)

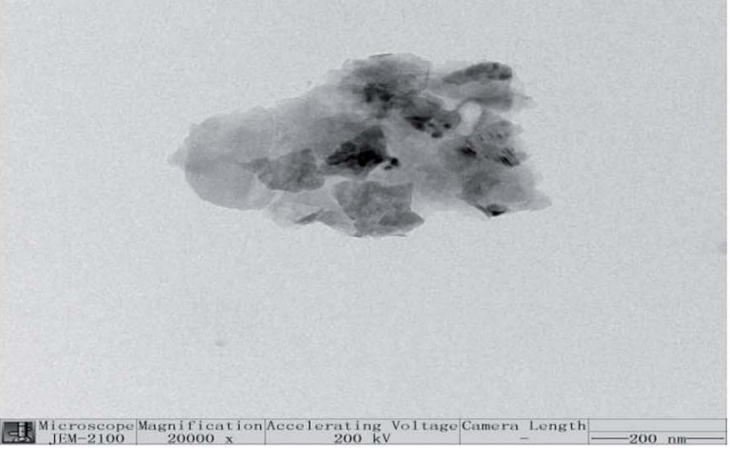

Fig. 1 AFM images (a) and thickness profiles (b) of $\mathrm{f}-\mathrm{MoS}_{2}$ nanosheets; TEM images of $\mathrm{f}-\mathrm{MoS} \mathrm{S}_{2}$ (c). 
(a)

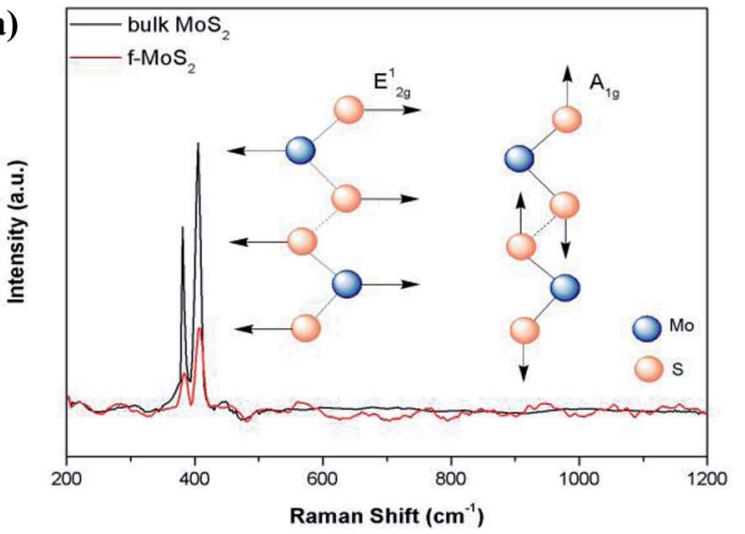

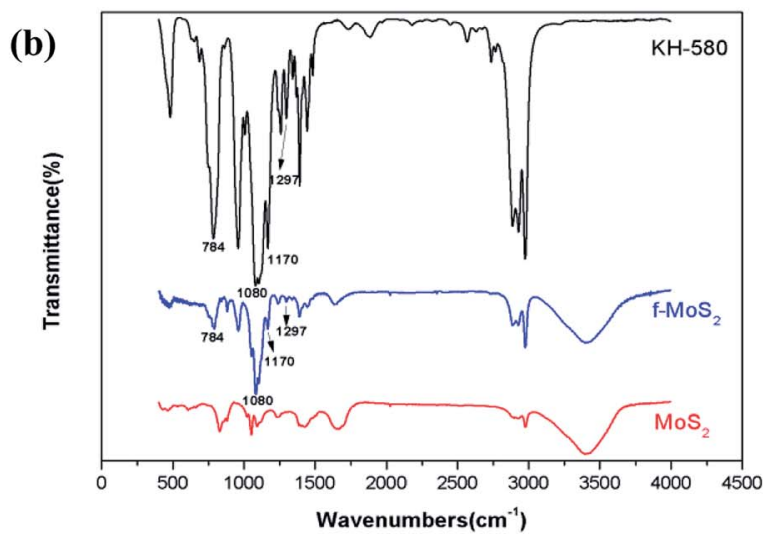

(c)

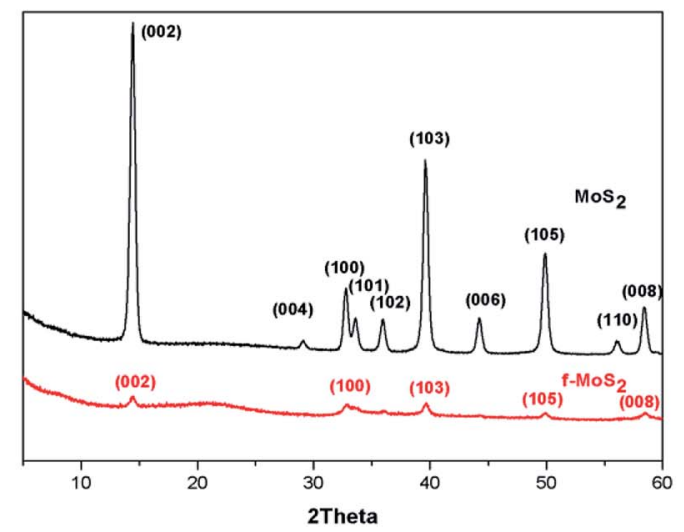

Fig. 2 (a) Raman spectrum of bulk $\mathrm{MoS}_{2}$ and f-MoS 2 nanosheets; (b) Fourier transform infrared spectra of KH580, MoS 2 and f-MoS ${ }_{2}$; (c) Powder $\mathrm{X}$-ray diffraction patterns of $\mathrm{MoS}_{2}$ and $\mathrm{f}-\mathrm{MoS}_{2}$.

ultrasonicated at ambient temperature for $4 \mathrm{~h}$. The epoxy resin was then added into the aforementioned dispersion and stirred under ultrasonic agitation for $6 \mathrm{~h}$. The solvent was gradually removed through heating the mixture on a magnetic hot plate with stirring. After the f-MoS $\mathrm{M}_{2}$ epoxy mixture had cooled to room temperature, the mixture was grinded 3 times by three roll mills. Subsequently, a low-viscosity curing agent (DMDC) was added, and a planetary vacuum mixer (ARV-310, Thinky) was used to blend the $\mathrm{f}-\mathrm{MoS}_{2}$ /epoxy slurry in a vacuum environment for $4 \mathrm{~min}$ at $1800 \mathrm{rpm}$. Finally, Teflon molds were used to cure the nanocomposite samples, cured for $2 \mathrm{~h}$ at $80{ }^{\circ} \mathrm{C}$ and post cured for $2 \mathrm{~h}$ at $150^{\circ} \mathrm{C}$.

\subsection{Characterization}

Transmission electron microscopy (TEM; JEM-2100, Japan Electron Optics Laboratory Co., Ltd.) was used to investigate the morphologies of the exfoliated f-MoS ${ }_{2}$ nanosheets. Atomic force microscopy (AFM) images of $\mathrm{f}-\mathrm{MoS}_{2}$ were obtained using a Being Nano-Instruments CSPM5500 in the tapping mode. The powder X-ray diffraction (XRD) patterns were recorded with a XRD-7000 Shimadzu X-ray diffractometer $(\mathrm{Cu} \mathrm{K} \alpha$ a radiation and $\lambda=0.1542 \mathrm{~nm}$ ), operating at $40 \mathrm{kV}$ voltage and $30 \mathrm{~mA}$ current. Laser Raman spectroscopy measurements were performed using a XploRA PLUS Raman microscope (HORIBA Scientific) with an excitation provided in back-scattering geometry by a $532 \mathrm{~nm}$ argon laser line. Fourier transform infrared (FTIR) spectra were recorded on a BRUKER TENSOR27 FTIR spectrometer using the KBr disc method. All the samples were analyzed with the transmission mode and the wavenumber range was set from 400 to $4000 \mathrm{~cm}^{-1}$. Dynamic mechanical analysis (DMA) was performed using a DMA Q800 apparatus (TA Instruments Inc.) at a fixed frequency of $1 \mathrm{~Hz}$ in the temperature range from room temperature to $200{ }^{\circ} \mathrm{C}$ at a linear heating rate of $5{ }^{\circ} \mathrm{C} \mathrm{min}^{-1}$. Morphology of the sample after being gold-sputtered was studied by a JEOL JSM-IT300 scanning electron microscope (SEM). The specimens of nanocomposites were cryogenically fractured in liquid nitrogen first and then sputter-coated with a conductive layer. Energy dispersive X-ray analysis (EDAX) was performed using a AMETEK ELEMENT. Static tensile loading tests (the thickness is 3.2 $\pm 0.4 \mathrm{~mm}$; The width is $10 \pm 0.2 \mathrm{~mm}$ ) and apparent shear strength tests (the thickness of the sheets is $1.62 \pm 0.125 \mathrm{~mm}$; the length of overlap is $12.7 \pm 0.25 \mathrm{~mm}$ ) were performed using an Instron 5982 universal testing system following the ASTM D638 standard and the ASTM D1002 standard, respectively. Impact resistance tests (sample size $80 \pm 2 \mathrm{~mm} \times 10 \pm 0.5 \mathrm{~mm}$ $\times 4 \pm 0.2 \mathrm{~mm}$ ) were conducted using a PTM1000 material testing system (SHENZHEN SUNS TECHNOLOGY STOCK CO., LTD.) following the ISO 179 standard. Five parallels for each sample were tested and the average value was reported. 


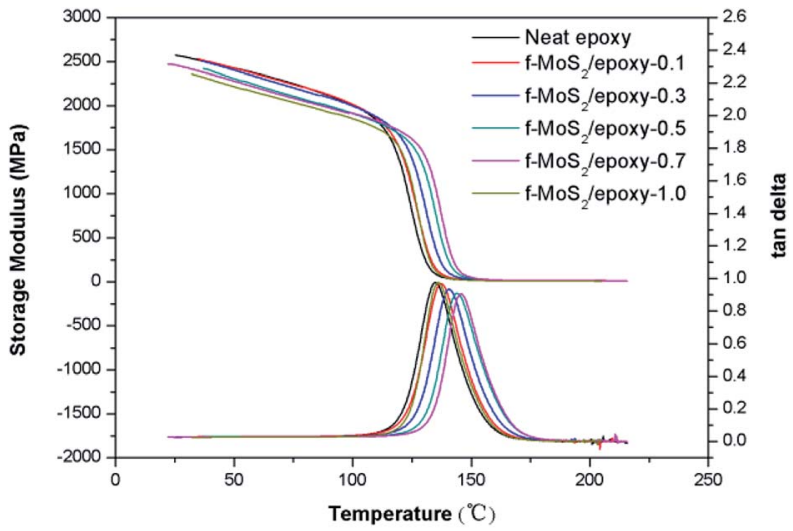

Fig. 3 Plots of storage modulus and tan delta versus temperature for neat epoxy and f-MoS $/$ /epoxy composites.

\section{Results and discussion}

\subsection{Characterization of $\mathrm{MoS}_{2}$ nanosheets}

To determine the average $\mathrm{f}-\mathrm{MoS}_{2}$ nanosheets thickness, we performed atomic force microscopy (AFM) scans as shown in Fig. 1a and b. The thickness of the f-MoS 2 nanosheets ranges from 1 to $6 \mathrm{~nm}$, while the average thickness of the monolayer
$\mathrm{MoS}_{2}$ is about $1 \mathrm{~nm}$ according to the previous reports. ${ }^{29,30}$ This indicates that the $\mathrm{f}-\mathrm{MoS}_{2}$ nanosheets in our study is composed of 1-6 layers of $\mathrm{MoS}_{2}$. The morphologies of $\mathrm{f}-\mathrm{MoS}_{2}$ nanosheets (Fig. 1c) were investigated by TEM. The lateral dimensions of $\mathrm{f}$ $\mathrm{MoS}_{2}$ nanosheets is about $300-500 \mathrm{~nm}$.

Raman spectra of the bulk $\mathrm{MoS}_{2}$ (Fig. 2a) shows modes at $380.9 \mathrm{~cm}^{-1}$ (the $\mathrm{E}_{2 \mathrm{~g}}^{1}$ mode corresponding to in-plane vibrations) and at $408.6 \mathrm{~cm}^{-1}$ (the $\mathrm{A}_{1 \mathrm{~g}}$ mode that corresponds to out-ofplane vibrations) which are characteristic modes of the trigonal prismatic structure of $\mathrm{MoS}_{2}$. For f-MoS${ }_{2}$, the $\mathrm{E}_{2 \mathrm{~g}}^{1}$ peak shifts to a higher frequency and the $\mathrm{A}_{1 \mathrm{~g}}$ peaks of $\mathrm{MoS}_{2}$ is transferred to a lower frequency, indicating that $\mathrm{f}-\mathrm{MoS}_{2}$ are thinner than bulk $\mathrm{MoS}_{2} \cdot{ }^{31-35}$

To determine the conjugation of KH580 and $\mathrm{MoS}_{2}$, Fourier transform infrared (FTIR) spectra were recorded as shown in Fig. 2b. Compared to pristine $\mathrm{MoS}_{2}$, the spectra of $\mathrm{f}-\mathrm{MoS}_{2}$ exhibit characteristic absorption bands at 1297, 1170, 1080 and $784 \mathrm{~cm}^{-1}$ which are attributed to the stretching vibration of $\mathrm{C}-$ $\mathrm{S}, \mathrm{C}-\mathrm{C}, \mathrm{Si}-\mathrm{O}$ and $\mathrm{Si}-\mathrm{C}$, respectively. These characteristic bands originate from $\mathrm{KH} 580$, which confirms the functionalization of KH580 on the $\mathrm{MoS}_{2}$.

Fig. 2c shows the powder XRD profiles of bulk $\mathrm{MoS}_{2}$ and $\mathrm{f}$ $\mathrm{MoS}_{2}$. The diffraction pattern of bulk $\mathrm{MoS}_{2}$ showed intense and (a)

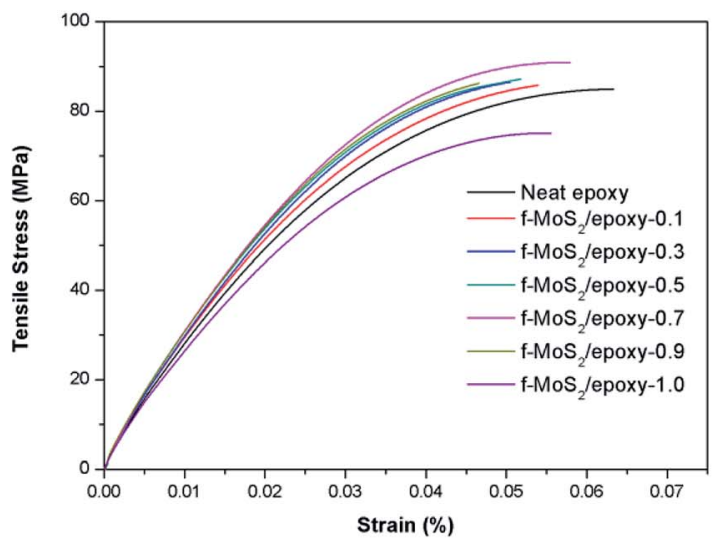

(c)

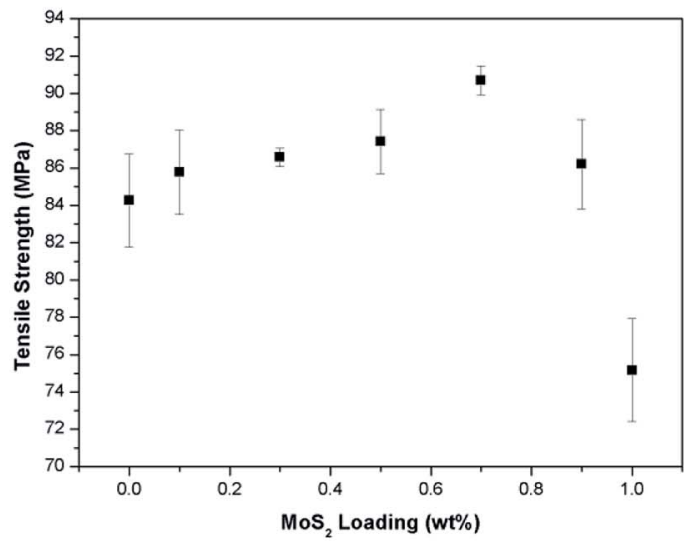

(b)

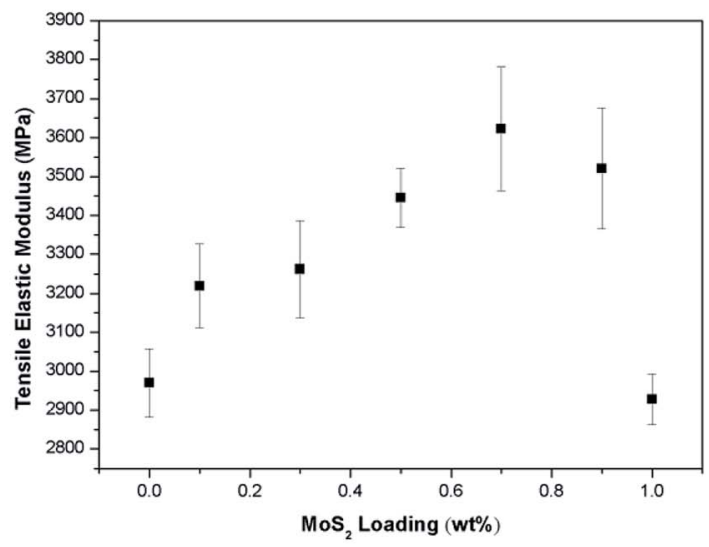

(d)

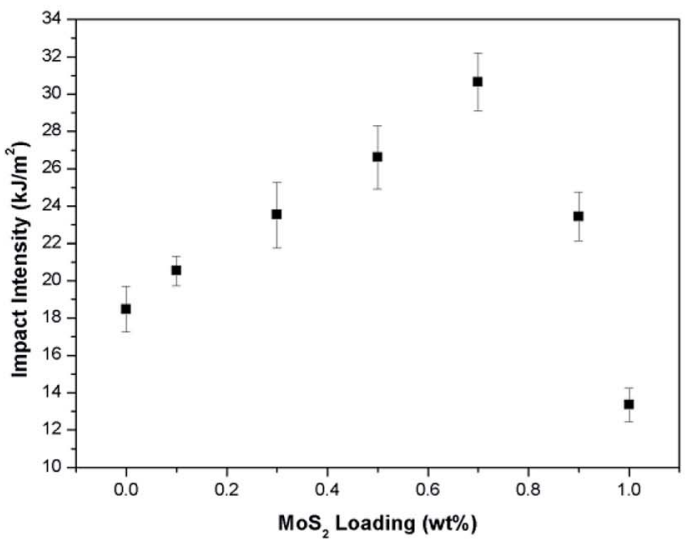

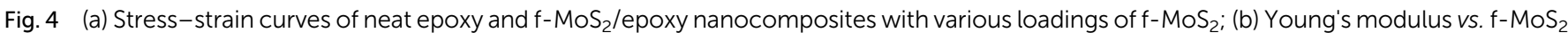
nanosheets loading fraction; (c) ultimate tensile strength vs. f-MoS $\mathrm{S}_{2}$ nanosheets loading fraction; (d) impact intensity vs. f-MoS 2 nanosheets loading fraction. 
(a)

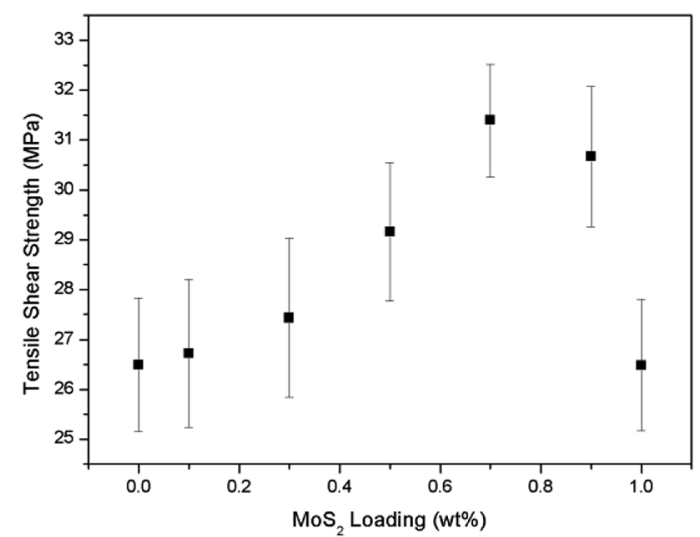

(b)

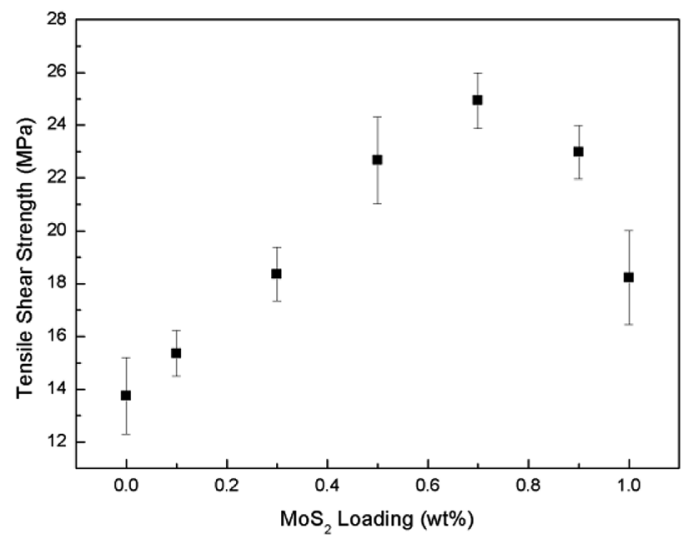

Fig. 5 (a) Apparent shear strength at room temperature vs. f-MoS $S_{2}$ nanosheets loading fraction; (b) apparent shear strength at $120{ }^{\circ} \mathrm{C}$ vs. $\mathrm{f}-\mathrm{MoS}_{2}$ nanosheets loading fraction.

sharp peaks at $14.48,32.78,39.76,49.96$, and 56.32 (2 theta), which correspond to the (002), (100), (103), (105), and (110) planes, respectively. All the characteristics bands of bulk $\mathrm{MoS}_{2}$ correspond well with the previous report. Post functionalization, the peaks corresponding to the (004), and (006) planes have disappeared. The (002) diffraction peak is still present at 14.4 for $\mathrm{f}-\mathrm{MoS}_{2}$, although the intensity of the peak has notably decreased. Low intensity peaks corresponding to the (100), (103), (105) and (008) planes can also be observed for f-MoS 2 . These features are in good agreement with disordered restacking of the exfoliated sheets during the drying process.
Additionally, the high quality exfoliated $\mathrm{MoS}_{2}$ nanosheets reported by predecessors still displayed prominent diffraction peaks. $^{36}$

The influence of $\mathrm{MoS}_{2}$ and $\mathrm{f}-\mathrm{MoS}_{2}$ on the dynamic mechanical thermal behaviors of the epoxy composites was investigated by DMA. Storage modulus curves and loss angle tangent of epoxy and its nanocomposites are presented in Fig. 3. The storage modulus is a measure of the stiffness, the storage modulus $\left(E^{\prime}\right)$ of the f-MoS $\mathrm{M}_{2}$ epoxy composites decreased with the increase of the $\mathrm{f}-\mathrm{MoS}_{2}$ loading. In the case of $\mathrm{f}-\mathrm{MoS}_{2} /$ epoxy-1.0, the storage modulus was about $7.31 \%$ lower than that of neat
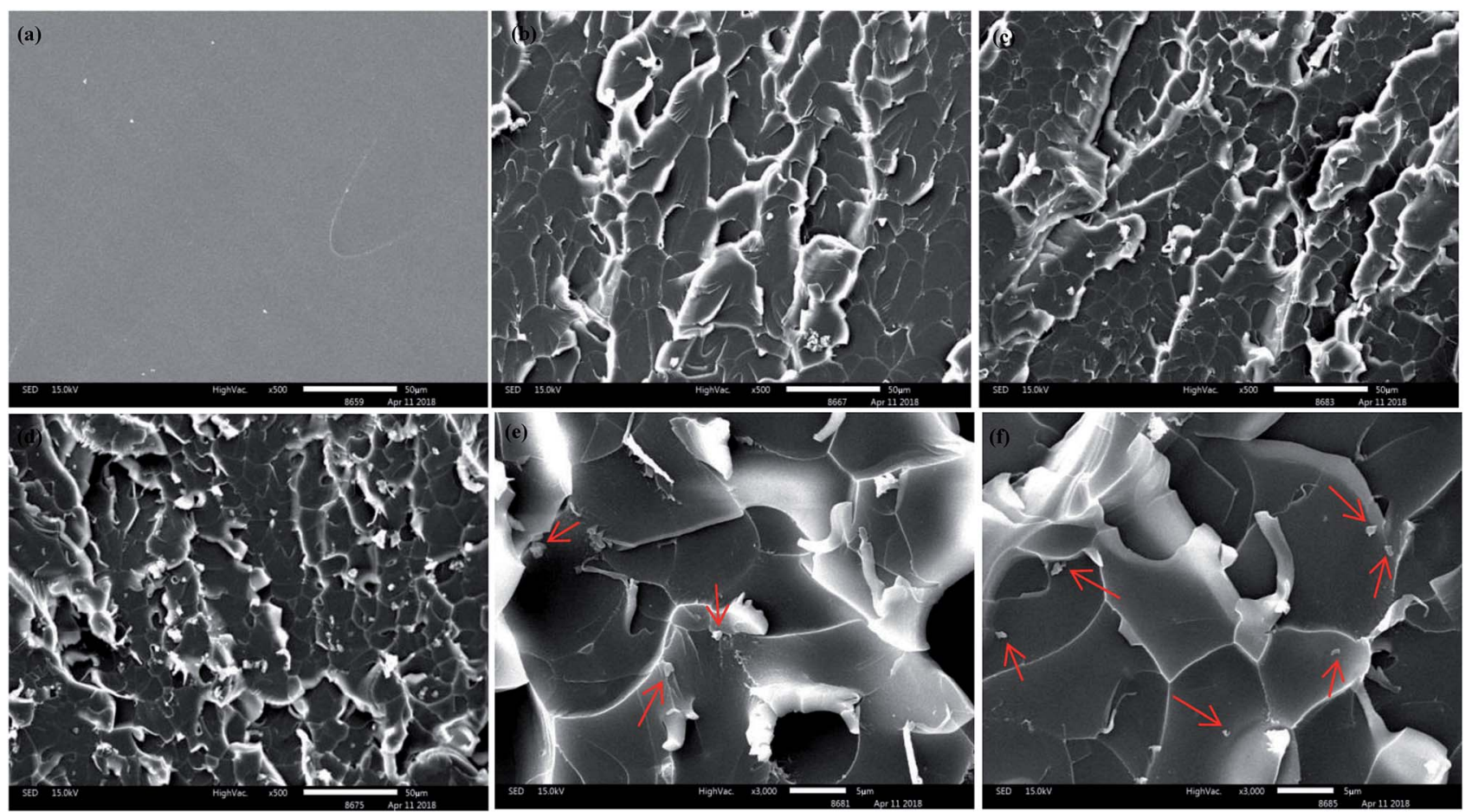

Fig. 6 Scanning electron microscopy images of the fracture surfaces of neat EP (a), $0.3 \mathrm{wt} \% \mathrm{f}-\mathrm{MoS}_{2} / \mathrm{epoxy}(\mathrm{b}), 0.7 \mathrm{wt} \% \mathrm{f}-\mathrm{MoS}_{2} / \mathrm{epoxy}$ (c and e) and $1.0 \mathrm{wt} \% \mathrm{f}-\mathrm{MoS}_{2} /$ epoxy ( $\mathrm{d}$ and f) nanocomposites. 


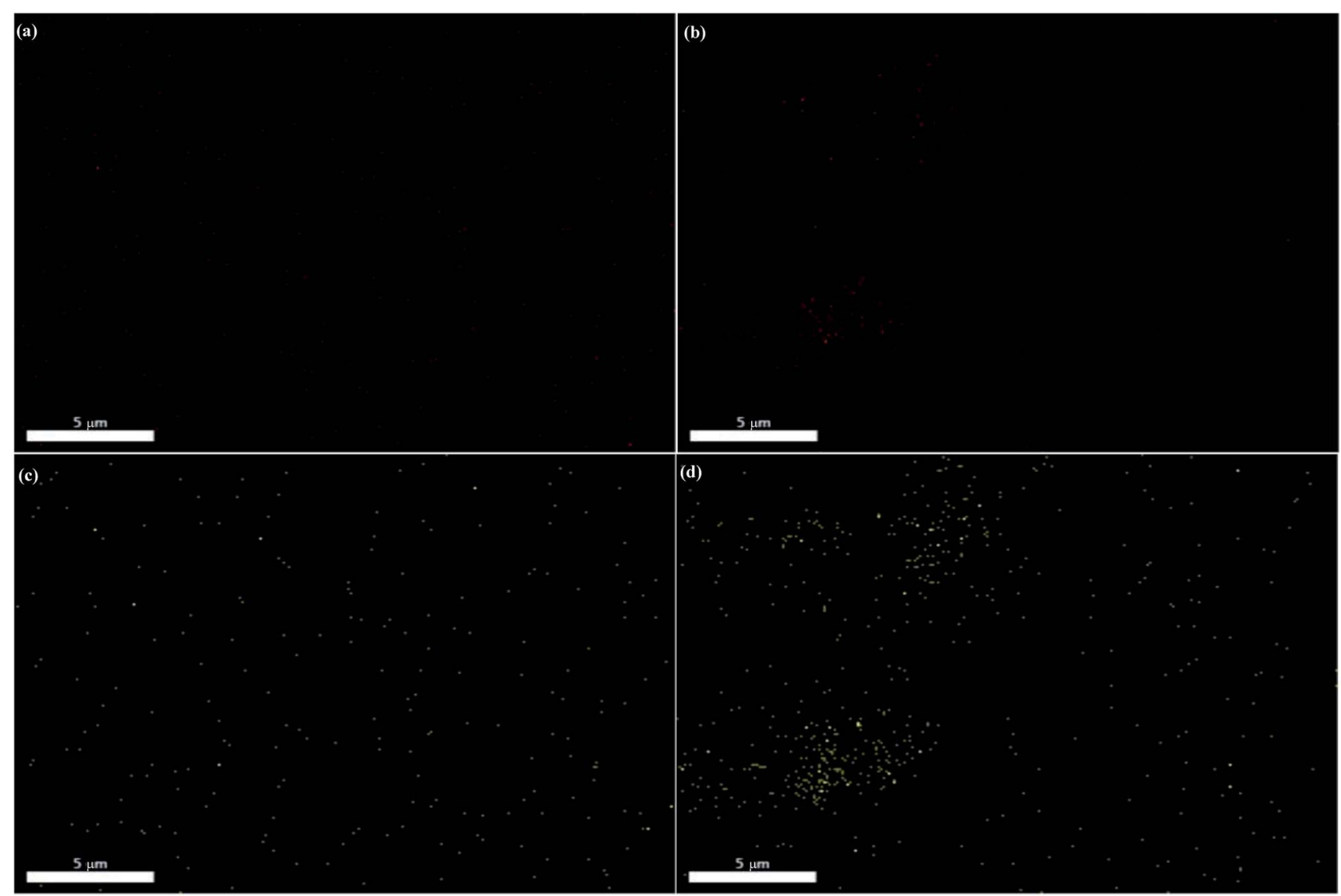

Fig. 7 Energy dispersive X-ray analysis images of the molybdenum element distribution mapping of 0.7 wt $\%$ f-MoS $/$ epoxy (a) and 0.7 wt\% bulk $\mathrm{MoS}_{2}$ /epoxy (b) nanocomposites, the sulfur element distribution mapping of $0.7 \mathrm{wt} \% \mathrm{f}-\mathrm{MoS}_{2} / \mathrm{epoxy}$ (c) and $0.7 \mathrm{wt} \%$ bulk MoS $/$ epoxy (d) nanocomposites.

epoxy at $35{ }^{\circ} \mathrm{C}$. Moreover, $E^{\prime}$ was generally decreased by the addition of $\mathrm{f}-\mathrm{MoS}_{2}$ in all temperature ranges. Incorporation of nanofillers into a polymer matrix can also affect its glass transition temperature $\left(T_{\mathrm{g}}\right)$. The glass transition temperature is determined by the peak of tan delta curves. The results indicate that the $T_{\mathrm{g}}$ increases significantly for the lower weight fraction composites, from $135{ }^{\circ} \mathrm{C}$ for the baseline (unfilled) epoxy to $146{ }^{\circ} \mathrm{C}$ at $0.7 \% \mathrm{f}^{-\mathrm{MoS}_{2}}$ loading. For the higher weight loadings up to $1.0 \%$, the $T_{\mathrm{g}}$ decreases to approximately that of the neat epoxy. Since the $T_{\mathrm{g}}$ is a thermal transition where polymer chain motion significantly increases, the increased $T_{\mathrm{g}}$ for the low weight fraction $\mathrm{f}_{-} \mathrm{MoS}_{2}$ nanocomposites is indicative of decreased chain mobility caused by interfacial interactions between the epoxy chains and the surfaces of the well dispersed f- $\mathrm{MoS}_{2}$ nanoplatelets additives. ${ }^{37,38}$ Conversely, at the higher loading fractions, the $\mathrm{f}-\mathrm{MoS}_{2}$ nanoplatelets will likely form agglomerates, resulting in fewer interfacial interactions and the matrix mobility therefore returns toward the value of the neat epoxy. ${ }^{39}$ The trend seen in the $T_{\mathrm{g}}$ response (Fig. 3 ) corresponds well to those seen for the high temperature apparent shear strength (Fig. 5b).

The typical stress-strain curves of the baseline epoxy and f$\mathrm{MoS}_{2}$ /epoxy nanocomposites are shown in Fig. 4a. Fig. 4b compares the Young's modulus of the pristine epoxy and the nanocomposite samples, and Fig. 4c shows their ultimate tensile strength. The error bars represent the maximum and minimum values obtained. The results indicate that $\mathrm{f}-\mathrm{MoS}_{2}$ nanosheets are effective at increasing the elastic modulus and the tensile strength of the epoxy at small nanosheets loadings (0.1-0.7\% by weight). The tensile modulus of $\mathrm{MoS}_{2} /$ epoxy composites increased from 2.97 to $3.62 \mathrm{GPa}$ (approximately a $22 \%$ increase over neat epoxy), and the tensile strength increased from 84.3 to $90.7 \mathrm{MPa}$ (approximately a $8 \%$ increase over neat epoxy) when the $\mathrm{MoS}_{2}$ content increased from 0 to $0.7 \%$. Moreover, as the $\mathrm{MoS}_{2}$ content increased from 0.7 to $1 \%$, the tensile modulus and tensile strength reduced to $2.93 \mathrm{GPa}$ and 75.2 $\mathrm{MPa}$, respectively. ${ }^{\mathbf{4 0 - 4 2}}$ There ported results are the average of 5 different tests for each $\mathrm{f}-\mathrm{MoS}_{2}$ nanosheets loading fraction.

As can be seen, the addition of $\mathrm{f}-\mathrm{MoS}_{2}$ nanosheets significantly improves the impact intensity of the epoxy matrix (Fig. 4d). It is strongly evident that even a small amount of $\mathrm{f}$ $\mathrm{MoS}_{2}$ nanosheets could significantly improve the mechanical strength. The maximum increase in impact intensity is $66 \%$ in the sample of $\mathrm{f}-\mathrm{MoS}_{2}$ /epoxy-0.7. However, beyond $0.7 \%$ loading there is a reduction in performance and at $1.0 \%$ loading the impact intensity of the nanocomposite sample reduced to 13.3 $\mathrm{kJ} \mathrm{m}{ }^{-2}$. 
The reinforcing effects of the $\mathrm{f}-\mathrm{MoS}_{2}$ on the adhesive properties of the epoxy composites are summarized in Fig. 5a and b. The apparent shear strength of $\mathrm{f}-\mathrm{MoS}_{2} /$ epoxy composites at room temperature increased from 26.5 to 31.4 MPa (approximately an $18 \%$ increase over neat epoxy), and the tensile shear strength at $120{ }^{\circ} \mathrm{C}$ increased from 13.8 to $24.9 \mathrm{MPa}$ (approximately an $80 \%$ increase over neat epoxy) when the $\mathrm{f}-\mathrm{MoS}_{2}$ nanosheets content increased from 0 to $0.7 \%$. However, beyond $0.7 \%$ loading there is a reduction in performance at room temperature and at $1 \%$ loading the performance of the nanocomposite sample is comparable to the baseline epoxy. ${ }^{\mathbf{4 3 , 4 4}}$

Moreover, as the $\mathrm{f}-\mathrm{MoS}_{2}$ nanosheets content increased from 0.7 to 0.9 and $1.0 \mathrm{wt} \%$, the apparent shear strength of the $\mathrm{f}$ $\mathrm{MoS}_{2}$ /epoxy composites at $120{ }^{\circ} \mathrm{C}$ turned to 22.9 and $18.2 \mathrm{MPa}$, respectively, but a reducing trend was observed on the apparent shear strength of the f-MoS$/$ /epoxy composites at $120{ }^{\circ} \mathrm{C}$.

To understand the dispersion levels of and $\mathrm{f}-\mathrm{MoS}_{2}$ in epoxy resin, the freeze-fractured surface microstructures (Fig. 6a-f) of epoxy nanocomposites were investigated by SEM. According to the previous studies, the fracture roughness of the polymer nanocomposites reflects the dispersion level and interfacial interaction to some degree. ${ }^{45,46}$ It can be observed in Fig. $6 a$ that the neat epoxy displays a smooth fracture surface. It is clear that the fracture surface roughness of the f-MoS 2 /epoxy nanocomposites increase with increasing addition of f-MoS ${ }_{2} \cdot{ }^{47-49}$ In addition, it is observed that numerous $\mathrm{MoS}_{2}$ agglomerates are pulled out of $1.0 \mathrm{wt} \% \mathrm{f}-\mathrm{MoS}_{2} /$ epoxy nanocomposite. Nevertheless, few $\mathrm{MoS}_{2}$ agglomerates emerge in the SEM images of $0.7 \mathrm{wt} \% \mathrm{f}-\mathrm{MoS}_{2}$ /epoxy nanocomposite because most of the $\mathrm{f}-\mathrm{MoS}_{2}$ nanosheets are uniformly embedded into the EP matrix.

To further verify the dispersion states of bulk $\mathrm{MoS}_{2}$ and f$\mathrm{MoS}_{2}$ in an epoxy matrix, the molybdenum and sulfur element distribution mapping of the bulk $\mathrm{MoS}_{2}$ /epoxy-0.7 and $\mathrm{f}-\mathrm{MoS}_{2} /$ epoxy-0.7 is provided in Fig. 7. In short, f-MoS $\mathrm{Manosheets}_{2}$ exhibit better dispersion in the epoxy matrix and compatibility with the matrix than those of bulk $\mathrm{MoS}_{2}$ because of the thinner structure and stronger interfacial interaction. ${ }^{\mathbf{5 0 , 5 1}}$ Undoubtedly, the resultant homogeneous dispersion of $\mathrm{f}-\mathrm{MoS}_{2}$ sheets in nanocomposites is beneficial to their reinforced performances.

Based on the results aforementioned, the high-efficiency reinforcement might be probably attributed to the uniform dispersion of the $\mathrm{f}-\mathrm{MoS}_{2}$ in the epoxy matrix (as observed in the EDAX images of Fig. 7a and c), as well as to the formation of strong interactive interfaces between $\mathrm{f}-\mathrm{MoS}_{2}$ and the epoxy matrix (as indicated in the SEM images of Fig. 6b-f). In the case of $\mathrm{f}-\mathrm{MoS}_{2}$ /epoxy nanocomposites, the exfoliated $\mathrm{f}-\mathrm{MoS}_{2}$ nanosheets with a high elastic modulus served as the reinforcement rather than the bulk $\mathrm{MoS}_{2}$ particles. The polymer chains adsorbed on the nanosheet surfaces are substantial due to the strong interfacial interactions, which increased the effective volume fraction of the reinforcement. The expansion of the effective volume fraction is presented to the continuous phase with consequences for adsorption and immobilization, ${ }^{52,53}$ which provided a high capacity for transferring the stress from the epoxy matrix to $\mathrm{f}-\mathrm{MoS}_{2}$ nanosheets.

\section{Conclusions}

In summary, functionalized $\mathrm{MoS}_{2}$ nanosheets were synthesized from bulk $\mathrm{MoS}_{2}$ via chemical exfoliation and subsequent surface modification with 3-mercaptopropyltriethoxysilane. The functionalized $\mathrm{MoS}_{2}$ were dispersed in epoxy polymers at loading fractions of up to wt $1 \%$ by ultrasonication and three roll mills. The dispersion states of $\mathrm{f}-\mathrm{MoS}_{2}$ in an epoxy matrix was much better than bulk $\mathrm{MoS}_{2}$ by EDAX and SEM. With only $0.7 \mathrm{wt} \%$ of $\mathrm{f}-\mathrm{MoS}_{2}$, a $22 \%$ increase in tensile elastic modulus, a $66 \%$ increase in impact intensity, an $80 \%$ increase in tensile shear strength at $120{ }^{\circ} \mathrm{C}$ and an $11{ }^{\circ} \mathrm{C}$ increment in glass transition temperature of the resultant $\mathrm{f}-\mathrm{MoS}_{2} /$ epoxy nanocomposite were attained. The superior reinforcing efficiency of f-MoS 2 can be attributed to the good dispersion of $\mathrm{MoS}_{2}$ sheets and the strong interfacial interaction with the polymer matrix enabled by surface functionalization of $\mathrm{MoS}_{2}$.

\section{Conflicts of interest}

There are no conflicts to declare.

\section{Notes and references}

1 X. Zhang, O. Alloul, Q. L. He, J. H. Zhu, M. J. Verde, Y. T. Li, S. Y. Wei and Z. H. Guo, Strengthened magnetic epoxy nanocomposites with protruding nanoparticles on the graphene nanosheets, Polymer, 2013, 54, 3594-3604.

2 O. Eksik, J. Gao, S. A. Shojaee, A. Thomas, P. Chow, S. F. Bartolucci, D. A. Lucca and N. Koratkar, Epoxy nanocomposites with two-dimensional transition metal dichalcogenide additives, ACS Nano, 2014, 8, 5282-5289.

3 W. L. Song, P. Wang, L. Cao, A. Anderson, M. J. Meziani, A. J. Farr and Y. P. Sun, Polymer/boron nitride nanocomposite materials for superior thermal transport performance, Angew. Chem., Int. Ed., 2012, 51, 6498-6501.

4 S. P. Pang, H. N. Tsao, X. L. Feng and K. Mullen, Patterned graphene electrodes from solution-processed graphite oxide films for organic field-effect transistors, Adv. Mater., 2009, 21, 3488-3491.

5 S. Stankovich, D. A. Dikin, G. H. B. Dommett, K. M. Kohlhaas, E. J. Zimney, E. A. Stach, R. D. Piner, S. T. Nguyen and R. S. Ruoff, Graphene-based composite materials, Nature, 2006, 442, 282-286.

6 H. Kim, A. A. Abdala, C. W. Macosko and W. M. Christopher, Graphene/polymer nanocomposites, Macromolecules, 2010, 43, 6515-6530.

7 A. Splendiani, L. Sun, Y. B. Zhang, T. S. Li, J. Kim, C. Y. Chim, G. Galli and F. Wang, Emerging photoluminescence in monolayer $\mathrm{MoS}_{2}$, Nano Lett., 2010, 10, 1271-1275.

8 K. Watanabe, T. Taniguchi and H. Kanda, Direct-bandgap properties and evidence for ultraviolet lasing of hexagonal boron nitride single crystal, Nat. Mater., 2004, 3, 404-409.

9 J. N. Coleman, M. Lotya, A. O'Neill, S. D. Bergin, P. J. King, U. Khan and K. Young, Two-dimensional nanosheets produced by liquid exfoliation of layered materials, Science, 2011, 331, 568-571. 
10 V. Nicolosi, M. Chhowalla, M. G. Kanatzidis, M. S. Strano and J. N. Coleman, Liquid exfoliation of layered materials, Science, 2013, 340, 1226419.

11 Z. Liu, L. Zhang, R. Wang, S. Poyraz, J. Cook, M. Bozack, S. Das, X. Zhang and L. Hu, Ultrafast microwave nanomanufacturing of fullerene-like metal chalcogenides, Sci. Rep., 2016, 6, 22503.

12 L. Zhang, W. Du, A. Nautiyal, Z. Liu and X. Zhang, Recent progress on nanostructured conducting polymers and composites: synthesis, application and future aspects, Sci. China Mater., 2018, 61, 303.

13 R. R. Chianelli, M. H. Siadati, M. P. D. Rosa, G. Berhault, J. P. Wilcoxon, R. Bearden and B. L. Abrams, Catalytic properties of single layers of transition metal sulfide catalytic materials, Catal. Rev.: Sci. Eng., 2006, 48, 1-41.

14 T. Polcar and A. Cavaleiro, Review on self-lubricant transition metal dichalcogenide nanocomposite coatings alloyed with carbon, Surf. Coat. Technol., 2011, 206, 686-695.

15 J. M. Soon and K. P. Loh, Electrochemical double-layer capacitance of $\mathrm{MoS}_{2}$ nanowall films, Electrochem. SolidState Lett., 2007, 10, A250-A254.

16 W. Zhang, P. Zhang, Z. Su and G. Wei, Synthesis and sensor applications of $\mathrm{MoS}_{2}$-based nanocomposites, Nanoscale, 2015, 7, 18364-18378.

17 M. R. Gao, Y. F. Xu, J. Jiang and S. H. Yu, Nanostructured metal chalcogenides: synthesis, modification, and applications in energy conversion and storage devices, Chem. Soc. Rev., 2013, 42, 2986-3017.

18 B. Radisavljevic, A. Radenovic, J. Brivio, V. Giacometti and A. Kis, Single-layer $\mathrm{MoS}_{2}$ transistors, Nat. Nanotechnol., 2011, 6, 147-150.

19 C. Q. Feng, J. Li, H. Ma, R. Zeng, Z. P. Guo and H. K. Liu, Synthesis of molybdenum disulfide $\left(\mathrm{MoS}_{2}\right)$ for lithium ion battery applications, Mater. Res. Bull., 2009, 44, 1811-1815.

20 S. Z. Butler, S. M. Hollen, L. Y. Cao, Y. Cui, J. A. Gupta, H. R. Gutierrez, T. F. Heinz, S. S. Hong, J. X. Huang and A. F. Ismach, Progress, challenges, and opportunities in two-dimensional materials beyond graphene, ACS Nano, 2013, 7, 2898-2926.

21 A. L. Elias, N. P. Lopez, A. C. Beltran, A. Berkdemir, R. T. Lv, S. M. Feng, A. D. Long, T. Hayashi, Y. A. Kim and M. Endo, Controlled synthesis and transfer of large-area $\mathrm{WS}_{2}$ sheets: from single layer to few layers, ACS Nano, 2013, 7, 5235-5242.

22 X. Wang, E. N. Kalali and D. Y. Wang, An in situ polymerization approach for functionalized $\mathrm{MoS}_{2} /$ nylon-6 nanocomposites with enhanced mechanical properties and thermal stability, J. Mater. Chem. A, 2015, 3, 24112-24120.

23 O. Eksik, J. Gao, S. A. Shojaee, A. Thomas, P. Chow, S. F. Bartolucci, D. A. Lucca and N. Koratkar, Epoxy nanocomposites with two-dimensional transition metal dichalcogenide additives, ACS Nano, 2014, 8, 5282-5289.

$24 \mathrm{~K}$. Chang and W. Chen, L-cysteine-assisted synthesis of layered $\mathrm{MoS}_{2}$ /graphene composites with excellent electrochemical performances for lithium ion batteries, ACS Nano, 2011, 5, 4720-4728.

$25 \mathrm{~K}$. Chang and W. X. Chen, In situ synthesis of $\mathrm{MoS}_{2}$ /graphene nanosheet composites with extraordinarily high electrochemical performance for lithium ion batteries, Chem. Commun., 2011, 47, 4252-4254.

26 K. C. Batista Mancinelli, F. D. S. Lisboa, J. F. Soares, S. F. Zawadzki and F. Wypych, Poly(vinyl alcohol) nanocomposite films containing chemically exfoliated molybdenum disulfide, Mater. Chem. Phys., 2013, 137, 764771.

27 N. Mirabal, P. Aguirre, M. Santa Ana, E. Benavente and G. Gonzáleza, Thermal stability and electrical conductivity in polyethers-molybdenum disulfide nanocomposites, Electrochim. Acta, 2003, 48, 2123-2127.

28 I. Saada and R. Bissessur, Nanocomposite materials based on chitosan and molybdenum disulfide, J. Mater. Sci., 2012, 47, 5861-5866.

29 D. J. Late, B. Liu, H. Matte, C. Rao and V. P. Dravid, Rapid characterization of ultrathin layers of chalcogenides on $\mathrm{SiO}_{2} / \mathrm{Si}$ substrates, Adv. Funct. Mater., 2012, 22, 1894-1905.

30 V. Štengl, J. Henych, M. Slušná and P. Ecorchard, Ultrasound exfoliation of inorganic analogues of graphene, Nanoscale Res. Lett., 2014, 9, 1-14.

31 K. P. Wang, J. Wang, J. T. Fan, M. Lotya, A. O'Neill, D. Fox, Y. Y. Feng, X. Y. Zhang, B. X. Jiang, Q. Z. Zhao, H. Z. Zhang, J. N. Coleman, L. Zhang and W. J. Blau, Ultrafast saturable absorption of two-dimensional $\mathrm{MoS}_{2}$ nanosheets, ACS Nano, 2013, 7, 9260-9267.

32 J. Q. Liu, Z. Y. Zeng, X. H. Cao, G. Lu, L. H. Wang, Q. L. Fan, W. Huang and $\mathrm{H}$. Zhang, Preparation of $\mathrm{MoS}_{2^{-}}$ polyvinylpyrrolidone nanocomposites for flexible nonvolatile rewritable memory devices with reduced graphene oxide electrodes, Small, 2012, 8, 3517-3522.

33 A. Splendiani, L. Sun, Y. Zhang, T. Li, J. Kim, C. Y. Chim, G. Galli and F. Wang, Emerging photoluminescence in monolayer MoS 2, Nano Lett., 2010, 10, 1271-1275.

34 L. L. Tao, H. Long, B. Zhou, S. F. Yu, S. P. Lau, Y. Chai, K. H. Fung, Y. H. Tsang, J. Q. Yao and D. G. Xu, Preparation and characterization of few-layer $\mathrm{MoS}_{2}$ nanosheets and their good nonlinear optical responses in the PMMA matrix, Nanoscale, 2014, 6, 9713-9719.

35 G. S. Bang, K. W. Nam, J. Y. Kim, J. Shin, J. W. Choi and S. Y. Choi, Effective liquid-phase exfoliation and sodium ion battery application of $\mathrm{MoS}_{2}$ nanosheets, ACS Appl. Mater. Interfaces, 2014, 6, 7084-7089.

36 M. A. Ibrahem, T. W. Lan, J. K. Huang, Y. Y. Chen, K. H. Wei, L. J. Li and C. W. Chu, High quantity and quality few-layers transition metal disulfide nanosheets from wet-milling exfoliation, RSC Adv., 2013, 3, 13193-13202.

37 J. R. Potts, D. R. Dreyer, C. W. Bielawski and R. S. Ruoff, Graphene-based polymer nanocomposites, Polymer, 2011, 52, 5-25.

38 Z. L. Yao, N. Braidy, G. A. Botton and A. Adronov, Polymerization from the surface of single-walled carbon nanotubes-preparation and characterization of nanocomposites, J. Am. Chem. Soc., 2003, 125, 16015-16024.

39 S. K. Kim, J. J. Wie, Q. Mahmooda and H. S. Park, Anomalous nanoinclusion effects of $2 \mathrm{D} \mathrm{MoS}_{2}$ and $\mathrm{WS}_{2}$ nanosheets on the mechanical stiffness of polymer nanocomposites, Nanoscale, 2014, 6, 7430-7435. 
40 M. A. Rafiee, J. Rafiee, Z. Wang, H. H. Song, Z. Z. Yu and N. Koratkar, Enhanced mechanical properties of nanocomposites at low graphene content, ACS Nano, 2009, 3, 3884-3890.

41 A. S. Zerda and A. J. Lesser, Intercalated clay nanocomposites: Morphology, mechanics, and fracture behavior, J. Polym. Sci., Part B: Polym. Phys., 2001, 39, 1137-1146.

42 K. Wang, L. Chen, J. S. Wu, M. L. Toh, C. B. He and A. F. Yee, Epoxy nanocomposites with highly exfoliated clay: Mechanical properties and fracture mechanisms, Macromolecules, 2005, 38, 788-800.

43 N. Illy, S. Benyahya, N. Durand, R. Auvergne, S. Caillol, G. David and B. Boutevin, The influence of formulation and processing parameters on the thermal properties of a chitosan-epoxy prepolymer system, Polym. Int., 2014, 63, 420-426.

44 S. Vadukumpully, J. Paul, N. Mahanta and S. Valiyaveettil, Flexible conductive graphene/poly(vinyl chloride) composite thin films with high mechanical strength and thermal stability, Carbon, 2011, 49, 198-205.

$45 \mathrm{H}$. Alamri and I. M. Low, Effect of water absorption on the mechanical properties of nano-filler reinforced epoxy nanocomposites, Mater. Des., 2012, 42, 214-222.

46 Y. X. Zhou, M. I. Jeelani and S. Jeelani, Development of photo micrograph method to characterize dispersion of CNT in epoxy, Mater. Sci. Eng., A, 2009, 506, 39-44.

47 M. Monti, M. Rallini, D. Puglia, L. Peponi, L. Torre and J. M. Kenny, Morphology and electrical properties of graphene-epoxy nanocomposites obtained by different solvent assisted processing methods, Composites, Part A, 2013, 46, 166-172.

48 L. C. Tang, Y. J. Wan, D. Yan, Y. B. Pei, L. Zhao, Y. B. Li, L. B. Wu, J. X. Jiang and G. Q. Lai, The effect of graphene dispersion on the mechanical properties of graphene/epoxy composites, Carbon, 2013, 60, 16-27.

49 D. Wang, K. Q. Zhou, W. Yang, W. Y. Xing, Y. Hu and X. L. Gong, Surface modification of graphene with layered molybdenum disulfide and their synergistic reinforcement on reducing fire hazards of epoxy resins, Ind. Eng. Chem. Res., 2013, 52, 17882-17890.

50 M. C. Hsiao, S. H. Liao, Y. F. Lin, C. A. Wang, N. W. Pu, H. M. Tsai and C. C. M. Ma, Preparation and characterization of polypropylene-graft-thermally reduced graphite oxide with an improved compatibility with polypropylene-based nanocomposite, Nanoscale, 2011, 3, 1516-1522.

51 J. J. Liang, Y. Huang, L. Zhang, Y. Wang, Y. F. Ma, T. Y. Guo and Y. S. Chen, Molecular-level dispersion of graphene into poly(vinyl alcohol) and effective reinforcement of their nanocomposites, Adv. Funct. Mater., 2009, 19, 2297-2302.

52 X. L. Ji, J. K. Jing, W. Jiang and B. Z. Jiang, Tensile modulus of polymer nanocomposites, Polym. Eng. Sci., 2002, 42, 983993.

53 B. Q. Chen and J. R. G. Evans, Nominal and effective volume fractions in polymer-clay nanocomposites, Macromolecules, 2006, 39, 1790-1796. 